\title{
Wet M1a non-small cell lung cancer: is it possible to predict recurrence of pleural effusion?
}

\author{
Fernando Conrado Abrao ${ }^{1}$, Igor Renato Louro Bruno de Abreu ${ }^{1}$, Geisa Garcia Viana ${ }^{2}$, Mariana Campello \\ de Oliveira ${ }^{2}$, Elnara Marcia Negri ${ }^{1}$, Riad Naim Younes ${ }^{1}$ \\ ${ }^{1}$ Oncology Center Hospital Alemão Oswaldo Cruz, Faculdade de Medicina Universidade, São Paulo, Brazil; ${ }^{2}$ Department of Thoracic Surgery, \\ Hospital Santa Marcelina, São Paulo, Brazil \\ Contributions: (I) Conception and design: FC Abrao, RN Younes; (II) Administrative support: EM Ngri, IR de Abreu; (III) Provision of study \\ materials or patient: GG Viana, MC de Oliveira; (IV) Collection and assembly of data: GG Viana, RN Younes, EM Negri; (V) Data analysis and \\ interpretation: FC Abrao, IR de Abreu; (VI) Manuscript writing: All authors; (VII) Final approval of manuscript: All authors. \\ Correspondence to: Fernando Conrado Abrao, MD. Oncology Center Hospital Alemão Oswaldo Cruz, Faculdade de Medicina Universidade, Rua \\ Sousa Ramos, 144, Apt 03 - Sao Paulo (SP), Brazil. Email: fernandocabrao@uol.com.br.
}

\begin{abstract}
Background: The propose was to recognize risk factors of malignant pleural effusion (MPE) recurrence in patients with symptomatic M1a non-small cell lung cancer (NSCLC).

Methods: All patients with NSCLC and MPE submitted to pleural palliative procedures were enrolled in a prospective study. Group I contained patients who had pleural recurrence, and Group II with no pleural recurrence. Prognostic factors for pleural recurrence were identified by univariable analysis, using Fisher's exact test for categorical variables and Student's $\mathrm{t}$ test for quantitative variables. Afterwards the significant variables were entered into a multivariable logistic regression analysis (with $\mathrm{P}<0.05$ considered significant). Receiver operating characteristics (ROC) analysis determined the cutoff points for continuous variables.

Results: A total of 82 patients were included in the analysis. There were 15 patients (18.3\%) in Group I and 67 patients $(81.7 \%)$ in Group II. Univariable analysis regarding factors affecting postoperative recurrence was: adenosine deaminase concentration in pleural fluid $<16 \mathrm{mg} / \mathrm{dL}(\mathrm{P}=0.04)$, albumin concentration in pleural fluid $<2.4 \mathrm{mg} / \mathrm{dL}(\mathrm{P}=0.03)$, administration of second-line palliative chemotherapy $(\mathrm{P}=0.018)$ and type of procedure [therapeutic pleural aspiration (TPA)] $(\mathrm{P}=0.023)$. At the multivariable analysis, only the type of procedure (TPA) $(\mathrm{P}=0.031)$ was identified as independent predictor of recurrence.

Conclusions: The identification of this factor may assist the choice of the optimal palliative technique; at the first episode of MPE in NSCLC patients and definitive procedure as pleurodesis or indwelling pleural catheter are recommended.
\end{abstract}

Keywords: Recurrence; palliative care; lung neoplasms

Submitted Jul 20, 2017. Accepted for publication Jan 03, 2018.

doi: $10.21037 /$ jtd.2018.01.53

View this article at: http://dx.doi.org/10.21037/jtd.2018.01.53

\section{Introduction}

Malignant pleural effusion (MPE) is frequent and given the continuous raise in new cancer diagnoses, the incidence is increasing $(1,2)$. MPE correspond to severe malignant disorder and poor quality of life $(3,4)$. It is known that MPE recurs rapidly, sometimes within a month after an initial thoracentesis in a considerable number of patients $(5,6)$. Treatment options are expanding and for this reason, a meticulous prognosis may help to recognize patients with a higher risk of pleural recurrence, aiming to individualize more intensive treatment strategies and, thus, minimize hardship in their terminal period of life $(7,8)$.

Regarding non-small cell lung cancer (NSCLC) patients, MPE occurs in approximately $15 \%$ of patients (9). Few studies have assessed MPE recurrence in NSCLC patients $(10-12)$ and aimed to evaluate the influence of systemic 
Table 1 Characteristics of the study population $(n=82)$

\begin{tabular}{|c|c|c|}
\hline Characteristic & $\mathrm{n}$ & $\%$ \\
\hline \multicolumn{3}{|l|}{ Gender } \\
\hline Female & 41 & 50.0 \\
\hline Male & 41 & 50.0 \\
\hline \multicolumn{3}{|l|}{ ASA } \\
\hline 1 & 1 & 1.2 \\
\hline 2 & 45 & 54.9 \\
\hline 3 & 33 & 40.2 \\
\hline 4 & 3 & 3.7 \\
\hline \multicolumn{3}{|l|}{ ECOG } \\
\hline 0 & 2 & 2.4 \\
\hline 1 & 24 & 29.3 \\
\hline 2 & 34 & 41.5 \\
\hline 3 & 17 & 20.7 \\
\hline 4 & 5 & 6.1 \\
\hline \multicolumn{3}{|l|}{ Primary site } \\
\hline Lung & 82 & 100.0 \\
\hline \multicolumn{3}{|l|}{ Procedure } \\
\hline Pleurodesis & 35 & 42.7 \\
\hline VAT/pleuroscopy & 11 & 13.4 \\
\hline Thoracocentesis & 30 & 36.6 \\
\hline Indwelling pleural catheter & 6 & 7.3 \\
\hline \multicolumn{3}{|l|}{ Pleural histology/cytology } \\
\hline Negative & 15 & 18.1 \\
\hline Positive & 63 & 65.9 \\
\hline \multicolumn{3}{|l|}{ Recurrence } \\
\hline No & 67 & 81.7 \\
\hline Yes & 15 & 18.3 \\
\hline \multicolumn{3}{|l|}{ Chemotherapy line } \\
\hline No treatment-first line palliative & 56 & 68.3 \\
\hline Chemotherapy palliative & 13 & 15.9 \\
\hline Chemotherapy palliative $>$ first line & 13 & 15.9 \\
\hline \multicolumn{3}{|l|}{ Metastasis } \\
\hline 0 & 34 & 44.2 \\
\hline 1 & 6 & 20.8 \\
\hline 2 & 17 & 21.2 \\
\hline$\geq 3$ & 10 & 13 \\
\hline
\end{tabular}

Metastasis: the number of metastatic sites was also evaluated, which was defined as presence of any numbers of metastasis at each organ. ASA, American Society of Anesthesiologists; ECOG: Eastern Cooperative Oncology Group performance status score; VAT, video-assisted thoracoscopy. treatment on MPE control. However, until these days, there have been no studies that evaluated factors associated with MPE relapse. The objective of this report was to recognize risk factors of recurrence only in symptomatic M1a NSCLC patients who required pleural approach.

\section{Methods}

A prospectively assembled database from our hospital, among January 2014 to July 2015, was analyzed to search stage IVa NSCLC patients with symptomatic MPE exposed to the first pleural approach. Pleural empyema, chylothorax and asymptomatic patients were excluded. The ethics committee of our institution authorized this research. The protocol number is 49258615.4 .

MPE was characterized as circumstances with malignant cells in pleural fluid, those with pleural infiltration recognized in the pathological evaluation or in patients with metastatic cancer at other locations validated by the pathological analyze and pleural effusion with no additional diagnosed causes after the review by the clinical team. Recurrence of pleural effusion was defined as the need for a new pleural procedure after the pleural palliative procedure. The need for a new pleural procedure was evaluated each 60 -day until one year after the inclusion of the last patient (January, 2017).

\section{Analyzed variables}

Preoperatively data were assembled to permit investigation of prognostic factors, which may impact recurrence. Obtained data included elementary demographics, body mass index (BMI) on the day before procedure, primary tumor site, American Society of Anesthesiologists (ASA) health status categorization, performance status according the Eastern Cooperative Oncology Group (ECOG) rating, white blood cells (WBC), neutrophils and lymphocytes, neutrophil/lymphocyte ratio (NLR), red blood cells (RBC) and platelets/lymphocyte ratio. Metastatic sites were also evaluated, which was defined as presence of any numbers of metastasis at each organ. Regarding postoperative period, we analyzed pleural effusion relapse, the palliative approach performed, the volume of drained liquid, the presence of malignant cells in the pleural fluid, in attachment to the biochemical profile comprehending adenosine deaminase (ADA), lymphocytes in pleural fluid, total protein, lactate dehydrogenase $(\mathrm{LDH})$, pleural $\mathrm{pH}$, glucose and albumin (Table 1). We also evaluated the presence of pleural 
thickening and pulmonary infiltrate through chest computed tomography. These characteristics were described as present or absent and identified in the chest computed tomography reports prior to the palliative procedure. Systemic treatment was also evaluated. Patients were classified into three groups at MPE diagnosis: systemic treatment-naive patients, patients who received first-line systemic treatment and patients receiving second-line systemic treatment or further therapy. Systemic treatment options were chosen at the discretion of the clinical oncology team and were not standardized. We collected survival data through oncologist team.

\section{Pleural procedure}

Pleural approach was determined according multidisciplinary meeting and according to the guidelines of the BTS-British Thoracic Society (7). Therapeutic pleural aspiration (TPA), defined as thoracocentesis for effusions of up to two-thirds of the hemithorax or small-bore chest tube for effusions that occupies more than two-thirds of the hemithorax, was applied in patients that multidisciplinary team considered developing pleural response to systemic treatment. TPA was also applied in patients with life expectancy shorter than 30 days, according British Thoracic Society and multidisciplinary team. The others patients received more aggressive procedures. High risk patients for general anesthesia were submitted a pleural drainage with chest tube. After full lung re-expansion and fluid drainage less than 200 milliliters/day pleurodesis was performed through the drain. Moreover, indwelling pleural drain was offered for patients judged incapable for general anesthesia from December 2014.

Patients handled under total anesthesia were underwent a video-assisted thoracoscopy (VAT). After suitable effusion samples were achieved for cytological analysis and culture, several considerable pleural fragments were captured from any irregular areas and if there are no irregular areas a number of random areas were sampled. Frozen-section histopathological analysis was performed if there is no preoperative cancer diagnosis. If full lung re-expansion was achieved, then pleurodesis was performed through insufflating $4 \mathrm{~g}$ of sterilized talc.

In patients which full lung re-expansion was not achieved the drain was removed five days after the procedure. All patients were evaluated monthly to verify pleural recurrence, which was defined as need for a new approach (thoracocentesis or indwelling drain). In our institution, we wait five days to remove the drain, in an attempt to expand the lung with physical therapy and allow pleurodesis with talc.

\section{Statistical analyses}

The patients were separated into two groups. Group I comprehended patients who had recurrence following the pleural approach and group II contained patients who did not have MPE recurrence after the pleural approach. The recognition of prognostic factors was accomplished through univariable analysis. We used Fisher's exact test for categorical variables and Student's $t$-test for quantitative variables. We considered $\mathrm{p}$ values of 0.1 or less as significant. Subsequently, all of these significant risk factors were included in the multivariable logistic regression analysis. This first model was refined through Wald test and Likelihood Ratio test to generate the conclusive model with the significant variables. We considered $\mathrm{p}$ values of 0.05 or less as significant. We used Hosmer-Lemeshow goodness of fit test to evaluate the model performance. Receiver operating characteristics (ROC) analysis determined the cutoff points for continuous variables through the point closest to the top-left part of the ROC analysis (13). We used the statistical software SPSS, version 20.0 (14) to realize statistical analyses.

\section{Results}

Eighty-two consecutive symptomatic patients were submitted to the first pleural approach for MPE during an 18-month period. All patient characteristics are demonstrated (Table 1). There were 11 patients with trapped lung, all diagnosed during the VAT procedure. None of the patients submitted to pleural drainage with local anesthesia (without VAT) for pleurodesis had trapped lung. The median follow-up was 89 (range, 2 to 1,070) days. Among patients that had MPE recurrence, the median survival was 201 (range, 29 to 603) days. MPE recurrence rate was $18.3 \%$. Among the patients who had MPE recurrence, the median pleural recurrence-free interval was 49 (range, 7 to 425) days (Figure 1).

Group I included 15 patients (recurrence) and group II included 67 patients (not recurrence). The procedures performed comprised 30 (36.5\%) TPA, 35 (42.6\%) pleurodesis, 11 VAT drainages without pleurodesis due to trapped lung (13.5\%) and six cases of indwelling pleural catheter (7.4\%). The median postoperative survival was 153 


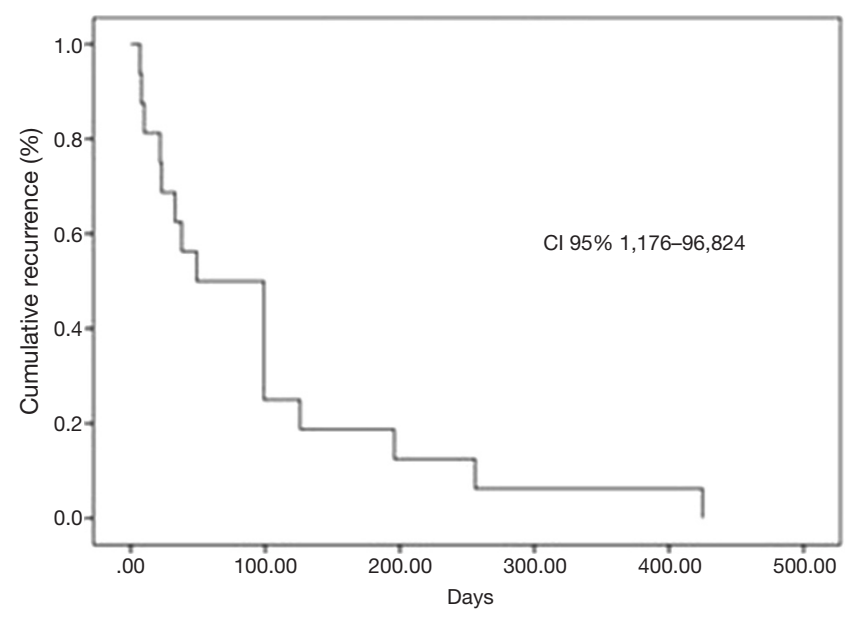

Figure 1 Kaplan-Meier recurrence curve among the patients who had malignant pleural effusion recurrence.

(2-618) days.

The univariable analysis of factors changing postoperative recurrence showed adenosine deaminase concentration in pleural fluid $<16 \mathrm{mg} / \mathrm{dL}(\mathrm{P}=0.04)$, albumin concentration in pleural fluid $<2.4 \mathrm{mg} / \mathrm{dL}(\mathrm{P}=0.03)$, administration of second-line palliative chemotherapy $(\mathrm{P}=0.018)$ and type of procedure (TPA vs. VAT, pleurodesis and indwelling pleural catheter) $(\mathrm{P}=0.023)$ (Table 2). At the multivariable analysis, only the type of procedure (TPA) $(\mathrm{P}=0.031)$ was identified as independent predictor of recurrence (Table 3 and Figure 2).

\section{Discussion}

Identifying factors associated to MPE recurrence at the diagnosis is important, as it can individualize the approach, preventing a negative impact on the adequate quality of life of these patients. There are few studies about MPE recurrence and the most studies only analyzed pleurodesis agents as the predictor of recurrence (15-19).

According to a recent meta-analysis, talc was compared with other sclerosing agents, indwelling pleural catheters, thoracoscopic mechanical pleurodesis and drainage alone. The success rate of talc pleurodesis was significantly higher than others therapies (relative risk, 1.21; 95\% CI, 1.01-1.45; $\mathrm{P}=0.035$ ) (20). Two randomized trials recently analyzed MPE recurrence. The TIME 1 randomized trial reported that pleurodesis through 12 French chest tube is more associated with higher MPE recurrence after 3 months than 24 French chest tube (30\% vs. 24\% difference, $-6 \%$; 1 -sided $95 \% \mathrm{CI},-20 \%$ to $\infty ; \mathrm{P}=0.14$ for noninferiority) (21).
The Time 2 randomized trial reported MPE recurrence comparing indwelling pleural catheter versus pleurodesis. This study reported lower risk of MPE recurrence with indwelling pleural catheter compared with talc pleurodesis (odds ratio $=0.21 ; 95 \% \mathrm{CI}, 0.04-0.86 ; \mathrm{P}=0.03$ ) (23). The relationship between biomarkers and MPE recurrence were also studied $(23,24)$. The report of Hsu et al compared pleural fluid concentrations of three biomarkers between patients who had MPE recurrence and patients who reached successful pleurodesis. The mean values were not significant between both groups: osteopontin $809.53 \pm 287.72$ vs. $361.54 \pm 71.80 \mathrm{ng} / \mathrm{mL} ; \mathrm{P}=0.151$, vascular endothelial growth factor (VEGF) 5,610.94 $\pm 2,040.61 \mathrm{vs}$. $3,564.96 \pm 1,044.12 \mathrm{pg} / \mathrm{mL} ; \mathrm{P}=0.383$ and urokinase-type plasminogen activator $99.04 \pm 53.88$ vs. $25.80 \pm 3.22 \mathrm{ng} / \mathrm{mL}$; $\mathrm{P}=0.198$ (24). As far as we know, our study is the first to evaluate risk factors for MPE recurrence only in NSCLC patients. We analyzed clinical, hematimetric, biochemical, radiological and surgical factors involved in MPE recurrence, specifically in NSCLC patients, identifying only TPA as an independent factor associated with MPE recurrence. Several guidelines and review articles recommend that TPA be used only in patients with short life expectancy, due to the high rate of recurrence associated with this technique $(7,25-28)$.

However, optimism towards recently published new and more effective systemic therapy for NSCLC might influence oncologists to indicate TPA as the treatment of choice at the first episode of MPE, including patients with life expectancy greater than 30 days. The present results do not support that approach, due to low control rate and increased likelihood of short-term recurrence. In our cohort, the median survival of patients with MPE recurrence was 201 [29-603] days. In this context, it is important to note that despite advances in the systemic treatment, it is not reasonable to deprive patients with a life expectancy greater than 30 days.

This result confirms the guidelines of the BTS (7), which do not recommend TPA as the sole treatment for patients with a life expectancy greater than 30 days. But even for patients with longer life expectancy, the BTS as well as some reviews $(7,25,29)$ recommend therapeutic thoracocentesis as the first approach to MPE. The aim would be to assess dyspnea relief. The final approach would be reserved in case of MPE recurrence. However, we know that these patients are receiving palliative treatment and, therefore, the fewer the procedures, the lower the psychological and physical stress. Furthermore, we observe 
Table 2 Univariate analysis of possible factors related $(\mathrm{n}=82)$

\begin{tabular}{|c|c|c|c|}
\hline \multirow{2}{*}{$\begin{array}{l}\text { Characteristic/ } \\
\text { group }\end{array}$} & \multicolumn{2}{|c|}{ Recurrence } & \multirow{2}{*}{$\mathrm{P}$} \\
\hline & No (\% or SD) & Yes (\% or SD) & \\
\hline Gender & & & 0.082 \\
\hline Female & $34(50.7)$ & $7(46.7)$ & \\
\hline Male & $33(49.3)$ & $8(53.3)$ & \\
\hline ASA & & & 0.161 \\
\hline 1 & $0(0.0)$ & $1(6.7)$ & \\
\hline 2 & $37(55.2)$ & 8 (53.3) & \\
\hline 3 & $28(41.8)$ & 5 (33.3) & \\
\hline 4 & $2(3.0)$ & $1(6.7)$ & \\
\hline ECOG & & & 0.529 \\
\hline 0 & $1(1.5)$ & $1(6.7)$ & \\
\hline 1 & $19(28.4)$ & 5 (33.3) & \\
\hline 2 & 27 (40.3) & $7(46.7)$ & \\
\hline 3 & $15(22.4)$ & $2(13.3)$ & \\
\hline 4 & $5(7.5)$ & $0(0.0)$ & \\
\hline Procedure & & & 0.023 \\
\hline Pleurodesis & $32(47.8)$ & $3(20.0)$ & \\
\hline VAT/pleuroscopy & $9(13.4)$ & $2(13.3)$ & \\
\hline Thoracocentesis & $20(29.9)$ & $10(66.7)$ & \\
\hline Pleurex & $6(9.0)$ & $0(0.0)$ & \\
\hline Pleural thickening & & & 0.673 \\
\hline No & $35(56.5)$ & $8(57.1)$ & \\
\hline Yes & $27(43.5)$ & $6(42.9)$ & \\
\hline Pulmonary infiltrate & & & 0.192 \\
\hline No & $34(55.7)$ & $10(71.4)$ & \\
\hline Yes & 27 (44.3) & $4(28.6)$ & \\
\hline Metastasis & & & 0.199 \\
\hline 0 & $29(46.0)$ & 5 (38.5) & \\
\hline 1 & $14(22.2)$ & $2(15.4)$ & \\
\hline 2 & $12(19.0)$ & $4(30.8)$ & \\
\hline$\geq 3$ & $8(12.7)$ & $2(14.4)$ & \\
\hline
\end{tabular}

Table 2 (continued)
Table 2 (continued)

\begin{tabular}{|c|c|c|c|}
\hline \multirow{2}{*}{$\begin{array}{l}\text { Characteristic/ } \\
\text { group }\end{array}$} & \multicolumn{2}{|c|}{ Recurrence } & \multirow{2}{*}{$P$} \\
\hline & No (\% or SD) & Yes (\% or SD) & \\
\hline \multicolumn{3}{|l|}{ Chemotherapy line } & \multirow[t]{4}{*}{0.016} \\
\hline $\begin{array}{l}\text { No treatment- } \\
\text { first line palliative }\end{array}$ & $49(73.1)$ & $6(42.9)$ & \\
\hline $\begin{array}{l}\text { Chemotherapy } \\
\text { palliative }\end{array}$ & $11(16.4)$ & $2(14.3)$ & \\
\hline $\begin{array}{l}\text { Chemotherapy } \\
\text { palliative > first } \\
\text { line }\end{array}$ & 7 (10.4) & $6(42.9)$ & \\
\hline \multicolumn{2}{|l|}{$\begin{array}{l}\text { Pleural histology/ } \\
\text { cytology }\end{array}$} & & \multirow[t]{3}{*}{0.933} \\
\hline Negative & $12(19.4)$ & $3(21.4)$ & \\
\hline Positive & $50(80.6)$ & $11(78.6)$ & \\
\hline Age (years) & $62.8(11.8)$ & $60.5(12.7)$ & 0.533 \\
\hline $\operatorname{BMI}\left(\mathrm{kg} / \mathrm{m}^{2}\right)$ & $25.1(4.8)$ & $27.2(13.3)$ & 0.452 \\
\hline ADA (IU/L) & 28.3 (122.9) & $11.5(8.6)$ & 0.024 \\
\hline $\mathrm{PH}$ & $7.61(0.7)$ & $7.7(0.2)$ & 0.576 \\
\hline LDH (IU/L) & 756.4 (855.3) & 1,053.3 (1,527.6) & 0.446 \\
\hline Glucose (g/dL) & $88.5(46.3)$ & $95.5(43.1)$ & 0.516 \\
\hline Albumin (g/dL) & $2.4(0.7)$ & $2.8(0.3)$ & 0.030 \\
\hline Protein (g/dL) & $4.0(1.1)$ & $4.0(1.0)$ & 0.567 \\
\hline $\begin{array}{l}\text { Effusion } \\
\text { lymphocytes (g/dL) }\end{array}$ & $56.4(30.5)$ & $65.4(26.4)$ & 0.214 \\
\hline hemoglobin (g/dL) & $11.9(2.2)$ & $11.8(1.5)$ & 0.302 \\
\hline Hematocrit (g/dL) & $36.4(6.5)$ & $36.2(4.0)$ & 0.426 \\
\hline Leukocytes $\left(10^{-9} / L\right)$ & $10,317.6(7,358.9)$ & $7,732.1(3,979.9)$ & 0.414 \\
\hline Neutrophils $\left(10^{-9} / \mathrm{L}\right)$ & $7,697.5(6,242.6)$ & $5,751.4(3,799.0)$ & 0.416 \\
\hline $\begin{array}{l}\text { Lymphocytes }\left(10^{-9} \text { / }\right. \\
\text { L) }\end{array}$ & $1561.6(770.8)$ & $1,148.8(519.4)$ & 0.594 \\
\hline NLR & $6.3(5.7)$ & $6.0(4.4)$ & 0.355 \\
\hline Platelets & $293,924(105,711)$ & $263,923(96,748)$ & 0.476 \\
\hline PLR & $243.2(173.8)$ & 301 (223.9) & 0.415 \\
\hline \multicolumn{4}{|c|}{$\begin{array}{l}\text { SD, standard deviation; ASA, American Society of } \\
\text { Anesthesiologists (ASA) physical status classification; ECOG, } \\
\text { Eastern Cooperative Oncology Group performance status score; } \\
\text { VAT, video-assisted thoracoscopy; BMI, body mass index; } \\
\text { ADA, adenosine deaminase; LDH, lactate dehydrogenase; NLR, } \\
\text { neutrophil/lymphocyte ratio; PLR, platelet/lymphocyte ratio. }\end{array}$} \\
\hline
\end{tabular}


Table 3 Independent predictors of recurrence at the multivariate analysis

\begin{tabular}{llll}
\hline \multirow{2}{*}{ Variable } & \multirow{2}{c}{$95 \% \mathrm{Cl}$ to EXP $(\mathrm{B})$} \\
\cline { 3 - 4 } & & Lower & Upper \\
\hline Chemotherapy Line & 0.300 & 0.659 & 3.254 \\
Albumin & 0.998 & 0.000 & 1.273 \\
ADA & 0.092 & 0.734 & 60.138 \\
Procedure & 0.031 & 0.084 & 0.885 \\
\hline
\end{tabular}

ADA, adenosine deaminase.

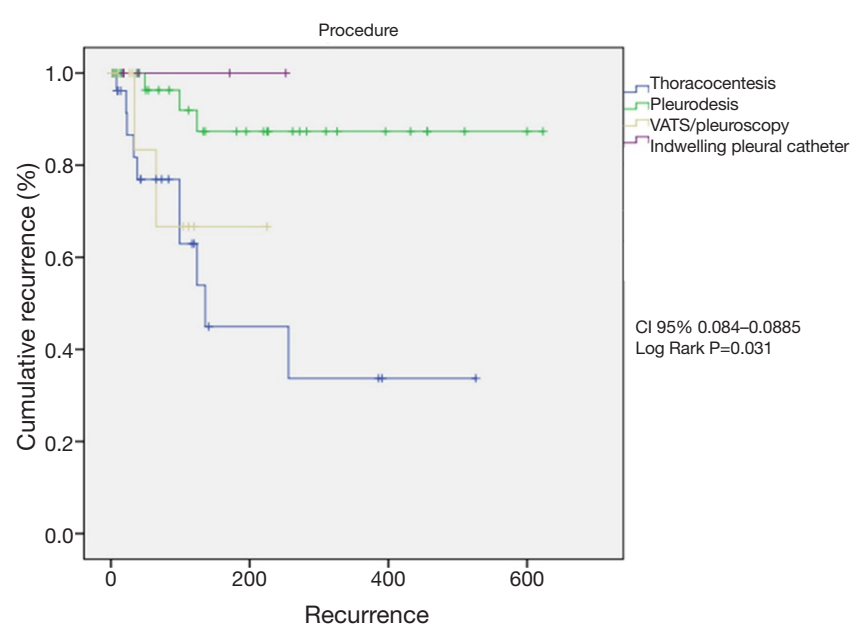

Figure 2 Kaplan-Meier recurrence curve comparing type of procedure.

in clinical practice that virtually all symptomatic patients have some degree of symptom improvement, even when there is another associated disease, such as pulmonary embolism or lymphangitis. That occurs because the dyspnea reflects reduced compliance of the chest wall, depression of the ipsilateral diaphragm, mediastinal shift and lung volume reduction (30), including patients with trapped lung. Therefore, it would be reasonable to avoid thoracentesis as the initial procedure when managing symptomatic patients with MPE associated with NSCLC and with a life expectancy greater than 30 days and offer definitive treatment, such as pleurodesis or indwelling pleural catheter.

As for the procedures not associated with MPE recurrence, they were indwelling pleural catheter, pleurodesis and surprisingly, the VAT with drain removal on the fifth postoperative day. We do not have knowledge of the biological mechanism to explain why the drainage by
VAT without pleurodesis is not associated with recurrence. On the contrary, many studies show that pleural drainage is associated with MPE recurrence; however, these studies referred to drainage at the bedside, without VAT (31-37). Furthermore, only Verma et al. reported eight patients treated with tyrosine kinase inhibitors that remained with the drain for 8 days and showed a median recurrence-free interval of 352 [12-739] days (10), although this study has a bias, namely the use of tyrosine kinase inhibitor. Perhaps the explanation is the occurrence of complete drainage of pleural fluid and drain positioning under direct view during the VAT, preventing shorerm re-accumulation. These two characteristics could facilitate spontaneous pleurodesis.

Some guidelines recommend only thoracentesis for tumors that respond to chemotherapy, such as lymphoma and ovarian cancer. However, there are few reports about the influence of systemic treatment on MPE recurrence, specifically in NSCLC $(10,11,12,38,39)$. In 2016, Usui et al., in a phase II study that included 30 patients with MPE treated with bevacizumab and carboplatinpemetrexed combination, reported a recurrence rate of $21.4 \%$ at the end of the study, with the median follow-up of 384 days (12). Regarding tyrosine kinase inhibitors, Lin et al. reported first-line treatment with tyrosine kinase inhibitors in patients with MPE and NSCLC, showing $43.4 \%$ of MPE recurrence (38) during a median follow-up period of 1,050 days. Our study did not evaluate any specific treatment such as the abovementioned ones, but the association between the systemic treatment phase in which the patient was and MPE recurrence. To our knowledge, this is the first study that analyzed this association. We found an association between patients at the second-line chemotherapy phase and MPE recurrence in the univariable analysis, only. Perhaps, if the numbers of patients evaluated were higher and systemic treatments were standardized, this result would have been confirmed in the multivariable analysis.

Our study has some limitations. The assessed population was referred to the thoracic surgery unit and did not represent all patients with MPE evaluated at our institution. Another important point is that we did not evaluate the effect of specific systemic therapies, such as targeted therapy or bevacizumab for the treatment of patients with NSCLC and MPE. Additionally, sample size was relatively small. However, our study included a restricted subgroup of patients with the same etiology of MPE.

We conclude that, in our sample, TPA was the only factor associated with MPE recurrence in NSCLC patients. 
Recurrence occurred in patients with life expectancy greater than 30 days and systemic treatment did not influence MPE recurrence. We do not favor TPA as the upfront treatment of MPE in NSCLC.

\section{Acknowledgements}

None.

\section{Footnote}

Conflicts of Interest: The authors have no conflicts of interest to declare.

Ethical Statement: The ethics committee of our institution authorized this research. The protocol number is 49258615.4 .

\section{References}

1. American Thoracic Society. Management of malignant pleural effusions. Am J Respir Crit Care Med 2000;162:1987-2001.

2. Cancer Statistics Registrations, England (Series MB1): Office of National Statistics, Stationary Office, 2010.

3. Antunes G, Neville E, Duffy J, et al. BTS guidelines for the management of malignant pleural effusions. Thorax 2003;58:ii29-38.

4. Antony VB, Loddenkemper R, Astoul P, et al. Management of malignant pleural effusions. Eur Respir J 2001;18:402-19.

5. Heffner JE, Klein JS. Recent advances in the diagnosis and management of malignant pleural effusions. Mayo Clin Proc 2008;83:235-50.

6. Shaw PH, Agarwal R. Pleurodesis for malignant pleural effusions. Cochrane Database Syst Rev 2013;11:CD002916.

7. Roberts ME, Neville E, Berrisford RG, et al. Management of a malignant pleural effusion: British Thoracic Society Pleural Disease Guideline 2010. Thorax 2010;65:ii32-40.

8. Tan C, Sedrakyan A, Browne J, et al. The evidence on the effectiveness of management for malignant pleural effusion: a systematic review. Eur J Cardiothorac Surg 2006;29:829-38.

9. Sugiura S, Ando Y, Minami H, et al. Prognostic value of pleural effusion in patients with non-small cell lung cancer. Clin Cancer Res 1997;3:47-50.

10. Verma A, Chopra A, Lee YW, et al. Can EGFR-Tyrosine
Kinase Inhibitors (TKI) Alone Without Talc Pleurodesis Prevent Recurrence of Malignant Pleural Effusion (MPE) in Lung Adenocarcinoma. Curr Drug Discov Technol 2016;13:68-76.

11. Tamiya M, Tamiya A, Yamadori T, et al. Phase 2 study of bevacizumab with carboplatin-paclitaxel for non-small cell lung cancer with malignant pleural effusion. Med Oncol 2013;30:676-82.

12. Usui K, Sugawara S, Nishitsuji M, et al. A phase II study of bevacizumab with carboplatin-pemetrexed in nonsquamous non-small cell lung carcinoma patients with malignant pleural effusions: North East Japan Study Group Trial NEJ013A. Lung Cancer 2016;99:131-36.

13. Perkins NJ, Schisterman EF. The inconsistency of 'optimal' cut-points using two ROC based criteria. Am J Epidemiol 2006;163:670-5.

14. IBM Corp. Released 2011. IBM SPSS Statistics for Windows, Version 20.0. Armonk, NY: IBM Corp.

15. Das SK, Saha SK, Das A, et al. A study of comparison of efficacy and safety of talc and povidone iodine for pleurodesis of malignant pleural effusions. J Indian Med Assoc 2008;106:589-590, 592.

16. Terra RM, Junqueira JJ, Teixeira LR, et al. Is full postpleurodesis lung expansion a determinant of a successful outcome after talc pleurodesis? Chest 2009;136:361-8.

17. Mohsen TA, Zeid AA, Meshref M, et al. Local iodine pleurodesis versus thoracoscopic talc insufflation in recurrent malignant pleural effusion: a prospective randomized control trial. Eur J Cardiothorac Surg 2011;40:282-6.

18. Demmy TL, Gu L, Burkhalter JE, et al. Optimal management of malignant pleural effusions (results of CALGB 30102). J Natl Compr Canc Netw 2012;10:975-82.

19. Stefani A, Natali P, Casali C, et al. Talc poudrage versus talc slurry in the treatment of malignant pleural effusion. A prospective comparative study. Eur J Cardiothorac Surg 2006;30:827-32.

20. Xia H, Wang XJ, Zhou Q, et al. Efficacy and Safety of Talc Pleurodesis for Malignant Pleural Effusion: A MetaAnalysis. PLoS One 2014;9:e87060.

21. Rahman NM, Pepperell J, Rehal S, et al. Effect of opioids vs NSAIDs and larger vs smaller chest tube size on pain control and pleurodesis efficacy among patients with malignant pleural effusion: The TIME1 Randomized Clinical Trial. JAMA 2015;314:2641-53.

22. Davies HE, Mishra EK, Kahan BC, et al. Effect of an indwelling pleural catheter vs chest tube and talc 
pleurodesis for relieving dyspnea in patients with malignant pleural effusion: the TIME2 randomized controlled trial. JAMA 2012;307:2383-9.

23. Pantazopoulos I, Xanthos, Vlachos I, et al. Pleural fluid glucose: A predictor of unsuccessful pleurodesis in a preselected cohort of patients with malignant pleural effusion. J BUON 2014;19:1018-23.

24. Hsu LH, Hsu PC, Liao TL, et al. Pleural fluid osteopontin, vascular endothelial growth factor, and urokinase-type plasminogen activator levels as predictors of pleurodesis outcome and prognosticators in patients with malignant pleural effusion: a prospective cohort study. BMC Cancer 2016;16:463.

25. Nam HS, Ryu JS. Diagnosis and management of malignant pleural effusion. Korean J Med 2011;81:167-73.

26. Liu C, Qian Q, Geng S, et al. Palliative treatment of malignant pleural effusion. Cancer Transl Med 2015;1:131-6.

27. Kaifi JT, Toth JW, Gusani NJ, et al. Multidisciplinary management of malignant pleural effusion. J Surg Oncol 2012;105:731-8.

28. Beyea A, Winzelberg G, Stafford RE. To drain or not to drain: an evidence-based approach to palliative procedures for the management of malignant pleural effusions. J Pain Symptom Manage 2012;44:301-6.

29. Zarogoulidis K, Zarogoulidis P, Darwiche K, et al. Malignant pleural effusion and algorithm management. J Thorac Dis 2013;5:S413-9.

30. Judson M, Sahn S. Pulmonary physiologic abnormalities caused by pleural disease. Semin Respir Crit Care Med 1995;16:346-53.

31. Sørensen PG, Svendsen TL, Enk B. Treatment of

Cite this article as: Abrao FC, de Abreu IR, Viana GG, de Oliveira MC, Negri EM, Younes RN. Wet M1a non-small cell lung cancer: is it possible to predict recurrence of pleural effusion? J Thorac Dis 2018;10(2):808-815. doi: 10.21037/ jtd.2018.01.53 malignant pleural effusion with drainage, with and without instillation of talc. Eur J Respir Dis 1984;65:131-5.

32. Zaloznik AJ, Oswald SG, Langin M. Intrapleural tetracycline in malignant pleural effusions. A randomized study. Cancer 1983;51:752-5.

33. Groth G, Gatzemeier U, Haussingen K, et al. Intrapleural palliative treatment of malignant pleural effusions with mitoxantrone versus placebo (pleural tube alone). Ann Oncol 1991;2:213-15.

34. Lambert CJ, Shah HH, Urshel HC Jr, et al. The treatment of malignant pleural effusions by closed trocar tube drainage. Ann Thorac Surg 1967;3:1-5.

35. Anderson CB, Philpott GW, Ferguson TB. The treatment of malignant pleural effusions. Cancer 1974;33:916-22.

36. Izbicki R, Weyhing BT 3rd, Baker L, et al. Pleural effusion in cancer patients. A prospective randomized study of pleural drainage with the addition of radioactive phosphorous to the pleural space vs. pleural drainage alone. Cancer 1975;36:1511-8.

37. Boland GW, Gazelle GS, Girard MJ, et al. Asymptomatic hydropneumothorax after therapeutic thoracentesis for malignant pleural effusions. AJR Am J Roentgenol 1998;170:943-6.

38. Lin JB, Lai FC, Li X, et al. Sequential treatment strategy for malignant pleural effusion in non-small cell lung cancer with the activated epithelial grow factor receptor mutation. J Drug Target 2017;25:119-24.

39. Tamiya M, Tamiya A, Yasue T, et al. vascular endothelial growth factor in plasma and pleural effusion is a biomarker for outcome after bevacizumab plus carboplatin-paclitaxel treatment for non-small cell lung cancer with malignant pleural effusion. Anticancer Res 2016;36:2939-44. 